\title{
LETTER
}

\section{The structure of hydrated copper-silicate gels, an analogue compound for natural chrysocolla}

\author{
Tsuyoshi Hariu, Hiroshi Arima and Kazumasa SugiYama \\ Institute for Materials Research (IMR), Tohoku University, 2-1-1 Katahira, Aoba-ku Sendai 980-8577, Japan
}

\begin{abstract}
Copper silicate hydrates have been prepared by sol-gel method using stock solutions with different $\mathrm{Cu} / \mathrm{Si}$ molar ratios. The synthetic gels were characterized by means of ICP-AES, TG-DTA, XRD, and EXAFS. Copper silicate hydrate gel having the chrysocolla-like structure was successfully formed in the gel samples prepared from every solution with different $\mathrm{Cu} / \mathrm{Si}$ molar ratios. The local structure of chrysocolla is readily realized in the copper silicate gels regardless of the $\mathrm{Cu} / \mathrm{Si}$ mol ratio involved.
\end{abstract}

Keywords: Chrysocolla, Cryptocrystalline, Local structure, Sol-gel synthesis

\section{INTRODUCTION}

Chrysocolla, cryptocrystalline copper-silicate with a proposed formula unit $\mathrm{Cu}_{2} \mathrm{H}_{2}\left(\mathrm{Si}_{2} \mathrm{O}_{5}\right)(\mathrm{OH})_{4} \cdot n \mathrm{H}_{2} \mathrm{O}$, is a secondary mineral occurring in the oxidized zones of copper deposits. Usually, natural chrysocolla sample is suggested to be formed by the precipitation of copper and silicon oxides on increase in $\mathrm{pH}$ of transporting solutions (Newberg, 1967). A previous XAFS study reported that chrysocolla contains $\mathrm{CuO}_{4}$ units which are arranged in the strip form together with adjacent tetrahedral units of $\mathrm{SiO}_{4}(\mathrm{Mc}-$ Keown, 1994). On the other hand, recent XAFS measurements led a completely different result that chrysocolla is not an independent mineral but a mixture of spertiniite $\left[\mathrm{Cu}(\mathrm{OH})_{2}\right]$, water and amorphous silica (Farges et al., 2007). In order to make a clear conclusion on this open question, X-ray diffraction study is strongly required. Nevertheless, chrysocolla shows a particularly broad Xray diffraction pattern and this does not allow us to conduct an ordinary single crystal X-ray diffraction study.

Taking into account of the unique molar ratio of $\mathrm{Cu} /$ Si for the natural chrysocolla sample, it is reasonable to consider that the production of natural chrysocolla is associated with a regular chemical reaction in the sedimentation process from the solution acquiring copper and silica components. And the understanding of the mineralization process of chrysocolla is expected to provide the useful information on the cryptocrystalline structure of

doi: 10.2465/jmps. $121022 \mathrm{c}$

H. Arima, arimah@imr.tohoku.ac.jp Corresponding author chrysocolla. This paper reports the synthesis and structural analysis of a synthetic analogue of chrysocolla prepared by the conventional sol-gel technique.

\section{EXPERIMENTAL}

Three hydrated copper silicate gels with different $\mathrm{Cu} / \mathrm{Si}$ molar compositions were prepared by the conventional sol-gel technique. $10 \mathrm{~g}$ of chemical regent $\mathrm{CuSO}_{4} \cdot 5 \mathrm{H}_{2} \mathrm{O}$ was dissolved in $300 \mathrm{ml}$ of a $0.1 \mathrm{M} \mathrm{HNO}_{3}$ (aq). $\mathrm{Si}\left(\mathrm{OC}_{2} \mathrm{H}_{5}\right)_{4}$ (TEOS, from Wako, Japan) was added drop wise to the $\mathrm{CuSO}_{4} / \mathrm{H}_{2} \mathrm{O} / \mathrm{HNO}_{3}$ solution so as to yield the stock sol-gel solutions having the $\mathrm{Cu} / \mathrm{Si}$ molar ratio of $0.50,1.0$, and 2.0, and then the hydrolysis reaction of TEOS was performed for $30 \mathrm{~min}$. Next, the $\mathrm{pH}$ value for the solutions was adjusted at 10 by adding $0.15 \mathrm{M} \mathrm{NH}_{3}$ (aq). $48 \mathrm{ml}$ of $1.1 \mathrm{M} \mathrm{NaOH}$ (aq) was added drop wise under stirring at $80{ }^{\circ} \mathrm{C}$ for 12 hours. The obtained gel samples were subsequently centrifuged and thoroughly washed with distilled water until the $\mathrm{pH}$ value of the filtrate reached to 7 . The gels, after drying in air at $100{ }^{\circ} \mathrm{C}$ for 12 hours, were homogenized by grinding in an agate mortar and used for the following examinations. The obtained gel powders prepared by the solutions having $\mathrm{Cu} /$ Si molar ratio of $0.50,1.0$, and 2.0 were hereafter named as $\mathrm{Cu} 1 \mathrm{Si} 2, \mathrm{Cu} 1 \mathrm{Si} 1$, and $\mathrm{Cu} 2 \mathrm{Si} 1$, respectively.

The actual $\mathrm{Cu}$ and $\mathrm{Si}$ concentrations for the gel samples were determined by inductively coupled plasma atomic emission spectrometry (ICP-AES, Thermo Fisher Scientific, IRIS Advantage DUO). The sample of $10 \mathrm{mg}$ was dissolved by the mixture of $5 \mathrm{~mL}$ of water, $5 \mathrm{~mL}$ of 
$\mathrm{HNO}_{3}$, and $0.5 \mathrm{~mL}$ of $\mathrm{HF}$ in a sealed Teflon container at room temperature. Palladium $(50 \mu \mathrm{g} / \mathrm{mL})$ and zinc $(10 \mu \mathrm{g} /$ $\mathrm{mL}$ ) solution of $10 \mathrm{~mL}$ was added as an internal standard, and the solution was diluted to $100 \mathrm{~mL}$. Standard solutions for the calibration curves were prepared with $\mathrm{HNO}_{3}$, HF, copper, and silicon and then treated by the similar procedure to those for the samples so as to correct matrix effects.

Thermogravimetric and differential thermal analysis (TG-DTA) was carried out with Rigaku TG-DTA 8120. About $10 \mathrm{mg}$ of each sample was weighed on a platinum crucible and heated up to $1000{ }^{\circ} \mathrm{C}$ in air with a heating rate of $10^{\circ} \mathrm{C} / \mathrm{min}$. Final products were examined by conventional powder $\mathrm{X}$-ray diffraction with $\mathrm{Cu}-K \alpha$ radiation $(\lambda=1.5405 \AA)$.

$\mathrm{X}$-ray diffraction measurement was carried out by using a conventional $\theta-2 \theta \mathrm{X}$-ray diffractometer equipped with a graphite monochrometor in the diffracted beam path (Rigaku RAD-B). Mo- $K \alpha$ radiation $(\lambda=0.71073 \AA)$ was used so as to obtain the diffraction intensity profile up to $Q=11.5 \AA^{-1}(Q=4 \pi \sin \theta / \lambda)$ for pair distribution function (PDF) analysis. After the corrections for absorption, polarization, and Compton scattering, the measured intensity patterns were normalized in electron units with the generalized Krogh-Moe-Norman method (Wagner et al., 1965) and PDF was obtained by the Fourier transformation of an interference function $Q i(Q)$ (Waseda, 1980).

The measurements of $\mathrm{Cu} \mathrm{K}$-edge XAFS spectra were carried out in transmission mode using in-house $\mathrm{X}^{-}$ ray absorption spectrometer (Rigaku R-XAS looper). Mo and $\mathrm{LaB}_{6}$ were respectively used as an $\mathrm{X}$-ray source target and an anode filament. The $\mathrm{X}$-ray beam was monochromatized by a Si (400) monochromator. The extended $\mathrm{X}$-ray absorption fine structure (EXAFS) interference functions, $\chi(k)$, were extracted from the measured absorption spectra using a software program Athena (Ravel and Newville, 2005), an interface to IFEFFIT (Newville, 2001).

\section{RESULTS AND DISCUSSION}

Table 1 summarizes the chemical composition of the synthetic gels determined by ICP-AES analysis. The $\mathrm{Cu} / \mathrm{Si}$ molar ratios of $\mathrm{Cu} 1 \mathrm{Si} 2, \mathrm{Cu} 1 \mathrm{Si} 1$, and $\mathrm{Cu} 2 \mathrm{Si} 1$ were 0.32 , 0.83 , and 1.61 respectively. The color of the gels changes from sky blue to dark blue with the increment of copper content. The $\mathrm{Cu} / \mathrm{Si}$ molar ratios of all gels fell as much as about $20-30 \%$ from those of the stock solutions. This result readily suggests that considerable amount of copper remains in the solution during the polymerization reaction in the present sol-gel process. It should be noted that the amount of the remaining copper in the solutions appears
Table 1. The chemical compositions (wt $\%$ ) of the gels and chrysocolla

\begin{tabular}{ccccc}
\hline Sample & $\mathrm{CuO}$ & $\mathrm{SiO}_{2}$ & \multicolumn{2}{c}{$\mathrm{Cu} /$ Si molar ratio $^{\mathrm{a}}$} \\
\hline $\mathrm{Cu} 1 \mathrm{Si} 2$ & 26.0 & 61.0 & 0.32 & $(0.50)$ \\
Cu1Si1 & 44.8 & 40.6 & 0.83 & $(1.0)$ \\
Cu2Si1 & 55.1 & 25.9 & 1.61 & $(2.0)$ \\
Chrysocolla $^{\mathrm{b}}$ & 40.3 & $36.1^{\mathrm{c}}$ & 0.84 & \\
\hline
\end{tabular}

Data were determined using ICP-AES. Chrysocolla is from Chuquicamata, Chile.

${ }^{\text {a }}$ Data of stock solutions are in parentheses.

${ }^{\mathrm{b}}$ Containing other components; $3.2 \mathrm{wt} \% \mathrm{CaO}, 1.1 \mathrm{wt} \% \mathrm{Al}_{2} \mathrm{O}_{3}, 0.3$ $\mathrm{wt} \% \mathrm{FeO}$, and $0.2 \mathrm{wt} \% \mathrm{ZnO}$.

${ }^{\mathrm{c}}$ Determined by gravimetry.

to be independent of the parent $\mathrm{Cu}$ content in the stock solutions. Assuming each difference of the deficient total weight $\%$ from 100 to be the water content, the molar ratio for $\mathrm{CuO}: \mathrm{SiO}_{2}: \mathrm{H}_{2} \mathrm{O}$ are $0.32: 1: 0.71,0.83: 1: 1.19$ and 1.61:1:2.45 for Cu1Si2, Cu1S1 and Cu2Si1, respectively. The chemical composition of natural chrysocolla from Chuquicamata, Chile is also shown in Table 1 for comparison. The corresponding ratio of $\mathrm{CuO}: \mathrm{SiO}_{2}: \mathrm{H}_{2} \mathrm{O}$ for the natural chrysocolla is $0.84: 1: 1.73$ and the $\mathrm{Cu} / \mathrm{Si}$ molar ratio, in particular, agrees well with as that of Cu1Si1.

The results of TG-DTA analysis are shown in Figure 1 together with that of natural chrysocolla. TG curves for Cu1Si2, Cu1Si1, Cu2Si1, and natural chrysocolla show a relatively smooth weight loss, totaling $19.0 \%, 22.0 \%$, $24.3 \%$, and $20.2 \%$, respectively. The value of the observed weight loss could be attributed to the water content estimated from the ICP-AES analysis, although some difference is observed probably due to the surface-adsorbed water of the obtained gels with very active surface structure. In the present PDF analysis, we utilized the water content estimated from the total weight loss observed in TG profile. The chemical composition used for the PDF analysis is shown in Figure 3.

The first two weight loss steps in the TG curves for our synthetic gel samples are consistent with the loss of water and dehydration of hydroxyls of natural chrysocolla samples (Frost et al., 2012). DTA curves of Cu1Si1 and natural chrysocolla show exothermic peaks at around 680 ${ }^{\circ} \mathrm{C}$, which correspond to the thermal decomposition reaction to form crystalline $\mathrm{CuO}$ (tenorite). Although exothermic peaks are not clearly shown in cases of $\mathrm{Cu} 1 \mathrm{Si} 2$ and $\mathrm{Cu} 2 \mathrm{Si1}$, similar reaction associated with the formation of $\mathrm{CuO}$ could be confirmed by heating them at $1000{ }^{\circ} \mathrm{C}$. Frost et al. (2012) pointed out that weight loss steps of natural chrysocollas are completely different from those of $\mathrm{Cu}(\mathrm{OH})_{2}$ (spertiniite) which is well known to show the thermal decomposition reaction at about $160{ }^{\circ} \mathrm{C}$. Thus, each of the synthetic gel samples is not a simple assem- 

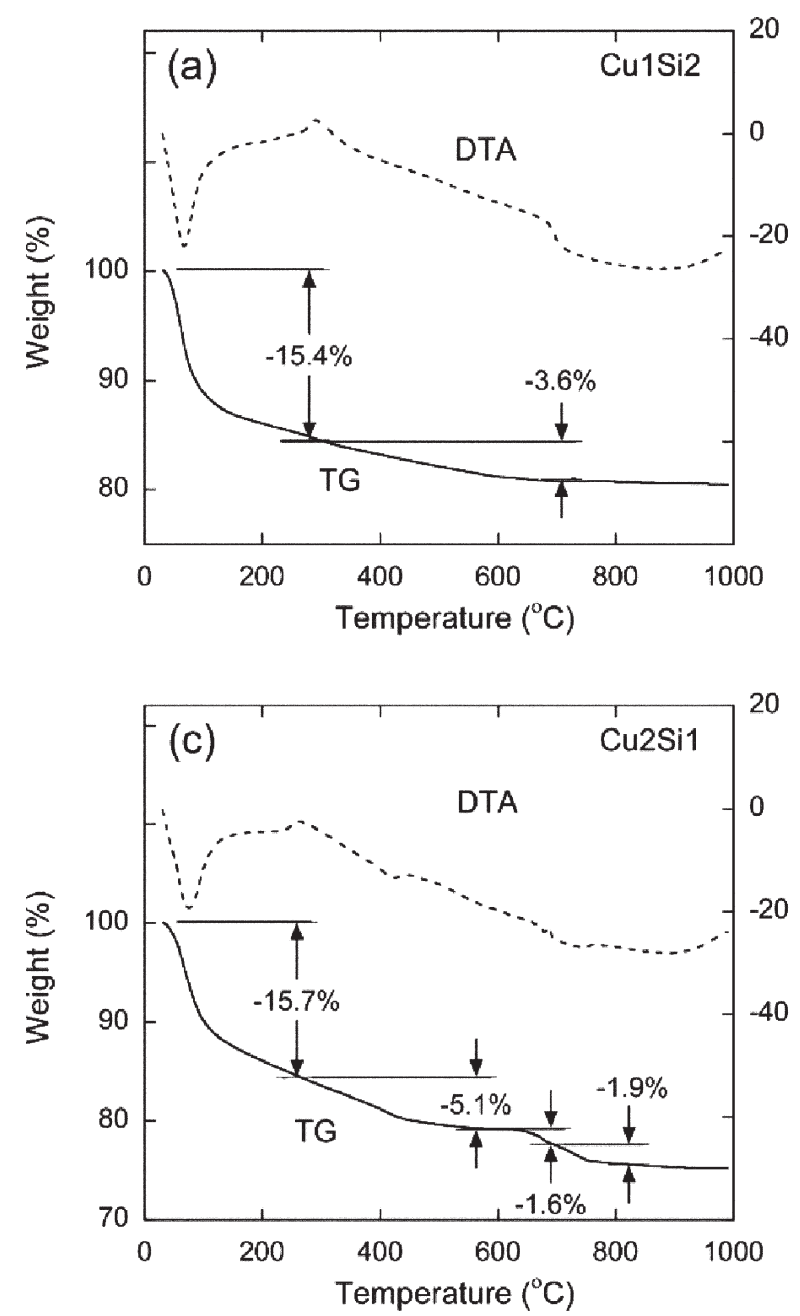

Figure 1. Curves of thermogravimetric and differential thermal analysis; (a) Cu1Si2, (b) Cu1Si1, (c) Cu2Si1, and (d) chrysocolla from Chuquicamata, Chile.

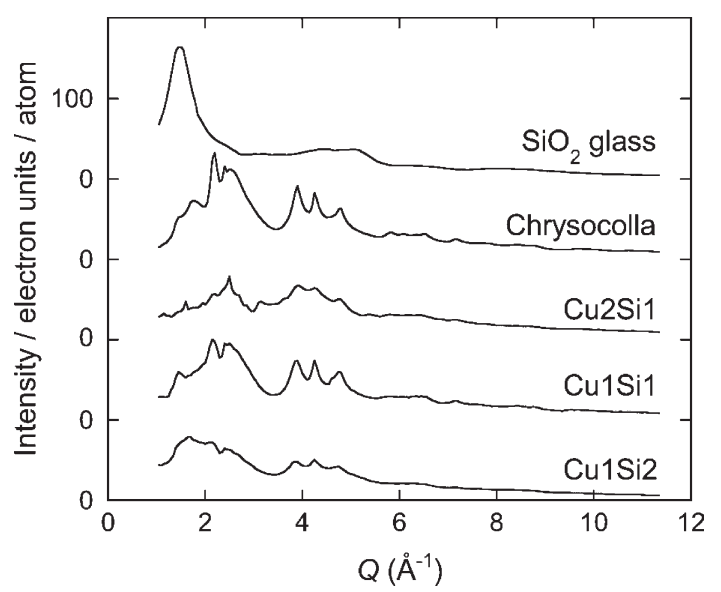

Figure 2. X-ray diffraction pattern of the gels. The pattern of chrysocolla from Chuquicamata, Chile and $\mathrm{SiO}_{2}$ glass are also shown for comparison. The horizontal axis indicates wave vector $(Q=4 \pi \sin \theta / \lambda)$.
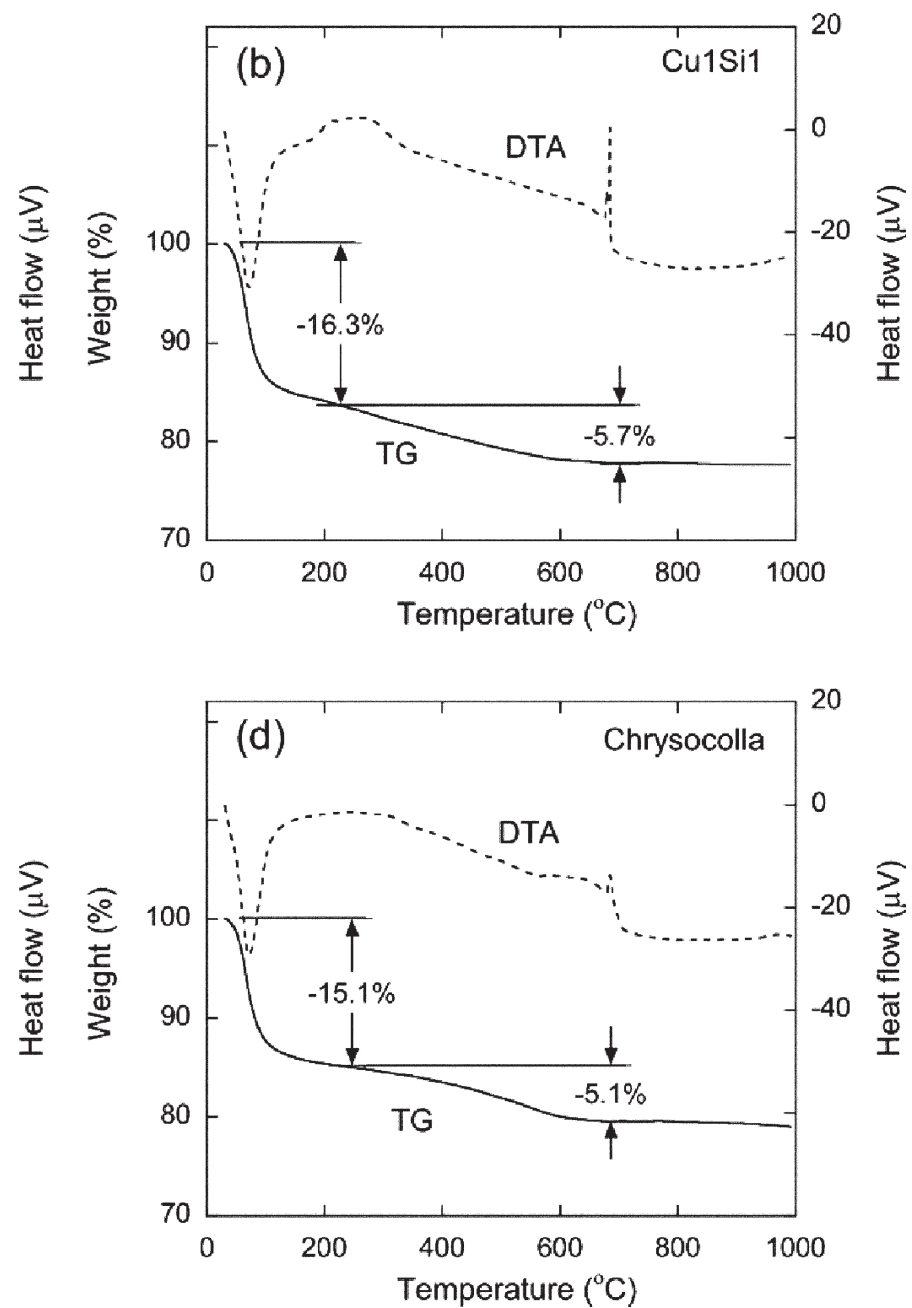

blage of spertiniite and amorphous or crystalline silica but it includes the substance similar to chrysocolla. At the same time, the additional weight loss at about $700{ }^{\circ} \mathrm{C}$ for Cu2Sil could be attributed to the decomposition of unknown compounds formed only when the copper content in the stock solution is much more than that of $\mathrm{SiO}_{2}$.

The XRD patterns for the three gel samples are shown in Figure 2 together with that of natural chrysocolla. Each pattern consists of a few diffuse maxima and several broad peaks are superimposed in them. Two profiles for $\mathrm{Cu} 1 \mathrm{Si} 2$ and $\mathrm{Cu} 1 \mathrm{Si} 1$ in Figure 2 indicate the three broad peaks at $Q=3.8,4.2$ and $4.6 \AA^{-1}$, which correspond well with those for natural chrysocolla. In particular, XRD pattern of Cu1Sil is quite similar to that of natural chrysocolla suggesting the gel Cu1Sil is isostructural with natural chrysocolla. The first diffuse maximum of $\mathrm{Cu} 1 \mathrm{Si} 2$ resides at about $1.6 \AA^{-1}$, which is apparently lower than those for the other gels. The first diffuse maxima of $\mathrm{Cu} 1 \mathrm{Si} 2$ well attributes to that of ordinary amorphous $\mathrm{SiO}_{2}$ 


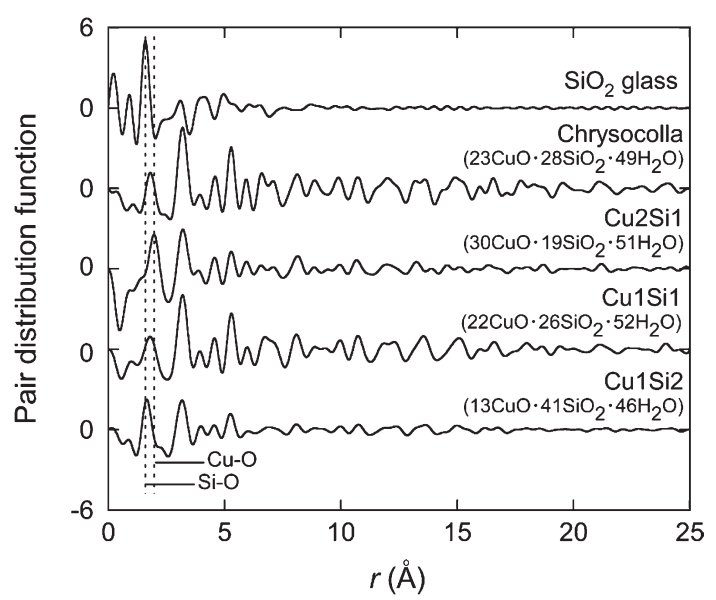

Figure 3. Reduced atomic pair distribution functions of the gels, chrysocolla from Chuquicamata, Chile, and $\mathrm{SiO}_{2}$ glass obtained by Fourier transformation of interference function with wavevector range $Q$ up to $11.5 \AA^{-1}$. Here $r$ is the radial distance. The dashed lines indicate the atomic distances for the tetrahedral $\mathrm{Si}-\mathrm{O}(1.61 \AA)$ and fourfold $\mathrm{Cu}-\mathrm{O}(1.97 \AA)$ pairs, as discussed in the text.

(Kamiya et al., 1998) or $\mathrm{SiO}_{2}$ glass (Mozzi and Warren, 1969). This feature allows us to consider that the part of $\mathrm{SiO}_{2}$ component in $\mathrm{Cu} 1 \mathrm{Si} 2$ encourages to form amorphous $\mathrm{SiO}_{2}, \mathrm{Si}(\mathrm{OH})_{4}, \mathrm{SiO}_{2} \cdot n \mathrm{H}_{2} \mathrm{O}$ and/or their intermediates. It may be noted that some sharp peaks at $Q=1.6,2.7$ and $2.8 \AA^{-1}$ for $\mathrm{Cu} 2 \mathrm{Si} 1$ could be assigned to those of planchéite $\left[\mathrm{Cu}_{8} \mathrm{Si}_{8} \mathrm{O}_{22}(\mathrm{OH})_{4} \cdot n\left(\mathrm{H}_{2} \mathrm{O}\right)\right]$ (Evans Jr. and Mrose, 1977).

Figure 3 shows the reduced RDF for $\mathrm{Cu} 1 \mathrm{Si} 2, \mathrm{Cu}-$ $1 \mathrm{Si1}$, and $\mathrm{Cu} 2 \mathrm{Sil}$ samples together with those for $\mathrm{SiO}_{2}$ glass (Sugiyama et al., 1989) and natural chrysocolla. The atomic correlation peaks for any pair of the constituents are clearly observed up to about $15 \AA$ for the cases of synthetic chrysocolla samples Cu2Si1, Cu1Si1, Cu1Si2 and natural chrysocolla. On the contrary, the atomic correlation in $\mathrm{SiO}_{2}$ glass becomes less distinct with the increasing correlation distance and disappears over $10 \AA$. Since the oscillations in reduced RDF well represent the degree of structural ordering, the obtained gels of $\mathrm{Cu} 1 \mathrm{Si} 2, \mathrm{Cu}-$ 1Si1 and Cu2Sil show the structures with middle-range orderings different from those for the common glasses. The dashed lines in Figure 3 indicate the atomic distances for the $\mathrm{Si}-\mathrm{O}$ in tetrahedral unit and $\mathrm{Cu}-\mathrm{O}$ in square planar, respectively, estimated from the ionic radii $\left({ }^{\mathrm{IV}} \mathrm{Si}^{4+}: 0.26 \AA\right.$, ${ }^{\text {IVsq. }} \mathrm{Cu}^{2+}: 0.62 \AA,{ }^{\mathrm{II}} \mathrm{O}^{2-}: 1.35 \AA$, Shannon and Prewitt, 1969). The first nearest-neighbor correlation in each gel represents a harmony of $\mathrm{Si}-\mathrm{O}$ and $\mathrm{Cu}-\mathrm{O}$ correlations and suggests the existence of $\mathrm{SiO}_{4}$ unit.

Figure 4 shows $\mathrm{Cu} K$-edge $k^{2}$-weighted $\chi(k)$ functions of the synthetic gel samples together with that for natural chrysocolla. Comparing oscillation behaviors in

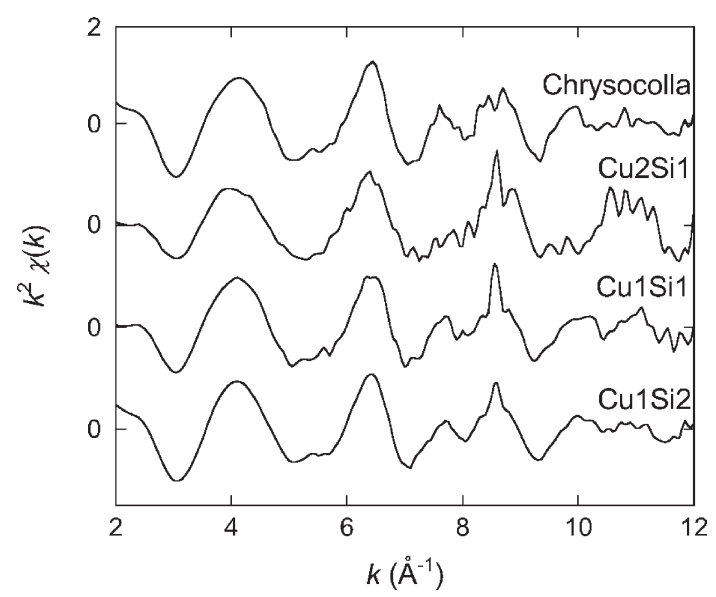

Figure 4. $\mathrm{Cu} K$-edge $k^{2}$-weighted $\chi(k)$ functions of the gels and chrysocolla from Chuquicamata, Chile.

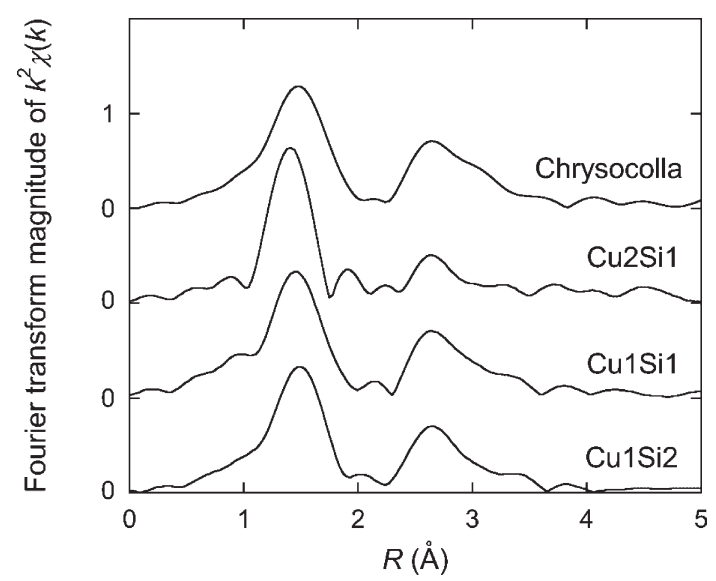

Figure 5. Radial structural functions obtained by Fourier transform of $k^{2}$-weighted $\chi(k)$ in the $k$ range from 3 to $12 \AA^{-1}$. Peak positions are not accord with interatomic distances because no phaseshift corrections are made.

$\chi(k)$ functions, spectra feature for $\mathrm{Cu} 1 \mathrm{Si} 2, \mathrm{Cu} 1 \mathrm{Si} 1$ and natural chrysocolla are characterized by oscillation peaks at $k=7.5 \AA^{-1}$ and $10 \AA^{-1}$, while these peaks are absent for $\mathrm{Cu} 2 \mathrm{Si1}$. These results indicate that local structure around $\mathrm{Cu}$ in $\mathrm{Cu} 1 \mathrm{Si} 2$ and $\mathrm{Cu} 1 \mathrm{Si} 1$ are similar to that of natural chrysocolla and that $\mathrm{Cu} 2 \mathrm{Si} 1$ has a unique $\mathrm{Cu}$ environment different from those of the others. Fourier transform of $k^{2}-$ weighted $\chi(k)$ function leads to more specific information on the local structure around $\mathrm{Cu}$. Figure 5 shows radial structural functions (RSF) obtained by Fourier transform of $k^{2}$-weighted $\chi(k)$ function in the $k$ range from 3 to 12 $\AA^{-1}$. According to McKeown (1994) and Farges et al. (2007), the main peak of RSF for natural chrysocolla centered near $1.4 \AA$ is considered to be the first nearest distance of $\mathrm{Cu}-\mathrm{O}$ in $\mathrm{CuO}_{4}$ square planar and the peak near $2.7 \AA$ corresponds to the distance of $\mathrm{Cu}-\mathrm{Cu}, \mathrm{Cu}-\mathrm{Si}$, or both. Although peak positions and intensities of the first 
nearest distances for $\mathrm{Cu} 1 \mathrm{Si} 2$ and Cu1Si1 differ slightly from that for natural chrysocolla, the environmental structure around $\mathrm{Cu}$ in $\mathrm{Cu} 1 \mathrm{Si} 2$ and $\mathrm{Cu} 1 \mathrm{Sil}$ are considered as $\mathrm{CuO}_{4}$ units and the linkage of the units is also similar to that of natural chrysocolla. It may be noted that the first peaks of RSF for $\mathrm{Cu} 2 \mathrm{Si} 1$ are almost equal to that of natural chrysocolla but significant difference could be observed in the intensity of the second peak. These results suggest the local structure of $\mathrm{CuO}_{4}$ in $\mathrm{Cu} 2 \mathrm{Si1}$, nevertheless there exist the connection of the $\mathrm{CuO}_{4}$ units which is different from that of natural chrysocolla and probably more complicated. Such structural difference in middlerange ordering is consistent with the existence of crystalline phases in $\mathrm{Cu} 2 \mathrm{Si} 1$.

\section{CONCLUDING REMARKS}

Copper silicate gels were synthesized via sol-gel precipitation from starting materials with different $\mathrm{Cu} / \mathrm{Si}$ molar composition. TG-DTA, XRD, and EXAFS measurements of the gels indicated that chrysocolla-like middle-range ordering is formed despite the variation in $\mathrm{Cu} / \mathrm{Si}$ molar ratio of starting stock solutions. In particular, the structural features of Cu1Si1 gel are almost perfectly equivalent to those of natural chrysocolla. Therefore, the authors believe that the stoichiometric composition of cryptocrystalline chrysocolla strongly depends on its short and medium range order and this unique middle-range ordering is formed as a result of chemical reaction in the precipitation induced by the increase in $\mathrm{pH}$. The local structural information of the $\mathrm{CuO}_{4}$ units around $\mathrm{Cu}$ together with the common $\mathrm{SiO}_{4}$ units observed in $\mathrm{Cu} 1 \mathrm{Sil}$ gel and natural chrysocolla allows us to consider the middle-range ordering such found in crystalline dioptase $\left(\mathrm{CuSiO}_{3} \cdot \mathrm{H}_{2} \mathrm{O}\right)$ and planchéite. However, linkages of $\mathrm{CuO}_{4}$ and $\mathrm{SiO}_{4}$ units in chrysocolla are still unknown and warrant further investigation using other techniques such as Raman spectroscopy to clarify the coordination environment of oxygen atoms and high-energy $\mathrm{X}$-ray diffraction measurements to obtain high-resolution PDF.

\section{ACKNOWLEDGMENTS}

A part of this work was supported by a Grant-in-Aid for
Challenging Exploratory Research (22656152) from the Japan Society for the Promotion of Science (JSPS).

\section{REFERENCES}

Evans Jr., H.T. and Mrose, M.E. (1977) The crystal chemistry of the hydrous copper silicates, shattuckite and planchéite. American Mineralogist, 62, 491-502.

Farges, F., Benzerara, K. and Brown, G.E. (2007) Chrysocolla redefined as spertiniite. AIP Conference Proceedings, 882, 223 225.

Frost, R.L., Xi, Y. and Wood, B.J. (2012) Thermogravimetric analysis, PXRD, EDX and XPS study of chrysocolla $(\mathrm{Cu}, \mathrm{Al})_{2} \mathrm{H}_{2} \mathrm{Si}_{2} \mathrm{O}_{5}(\mathrm{OH})_{4} \cdot \mathrm{nH}_{2} \mathrm{O}$-structural implications. Thermochimica Acta, 545, 157-162.

Kamiya, K., Dohkai, T., Wada, M., Hashimoto, T., Matsuoka, J. and Nasu, H. (1998) X-ray diffraction of silica gels made by sol-gel method under different conditions. Journal of NonCrystalline Solids, 240, 202-211.

McKeown, D.A. (1994) X-ray absorption spectroscopic study of copper in an amorphous copper silicate: chrysocolla. Journal of Non-Crystalline Solids, 180, 1-10.

Mozzi, R.L. and Warren, B.E. (1969) The structure of vitreous silica. Journal of Applied Crystallography, 2, 164-172.

Newberg, D.W. (1967) Geochemical implications of chrysocollabearing alluvial gravels. Economic Geology, 92, 932-956.

Newville, M. (2001) IFEFFIT: interactive EXAFS analysis and FEFF fitting. Journal of Synchrotron Radiation, 8, 322-324.

Ravel, B. and Newville, M. (2005) ATHENA, ARTEMIS, HEPHAESTUS: data analysis for X-ray absorption spectroscopy using IFEFFIT. Journal of Synchrotron Radiation, 12, 537-541.

Shannon, R.D. and Prewitt, C.T. (1969) Effective ionic radii in oxides and fluorides. Acta Crystallographica, B25, 925-946.

Sugiyama, K., Matsubara, E., Suh, I.K., Waseda, Y. and Toguri, J.M. (1989) Determination of the structural parameters of local ordering in oxide melts and glasses from X-ray diffraction data. Science reports of the Research Institutes, Tohoku University. Ser. A, Physics, chemistry and metallurgy, 34, 143-154.

Wagner, C.N.J., Ocken, H. and Joshi, M.L. (1965) Interference and radial distribution functions of liquid copper silver, tin and mercury. Zeitschrift für Naturforschung A, 20, 325-335.

Waseda, Y. (1980) The Structure of non-crystalline materials. McGraw Hill, New York.

Manuscript received October 22, 2012

Manuscript accepted March 4, 2013

Manuscript handled by Keiji Shinoda 